\title{
ESTRUCTURA RÍTMICA Y MOTIVACIÓN DE ALGUNOS JUEGOS VERBALES CON RIMAS EN EL ESPAÑOL DE MÉXICO*
}

\author{
Erik Daniel Franco Trujillo \\ El Colegio de México \\ efranco@colmex.mx
}

\begin{abstract}
Resumen: En este trabajo presento un primer acercamiento a la descripción de 169 juegos verbales con rimas que he podido documentar en el español mexicano. Tras caracterizar la noción de juego verbal, considero estas prácticas discursivas desde su dimensión como actos de habla. Posteriormente, realizo un análisis centrado en determinar el número de sílabas, el patrón rítmico y la motivación de estos juegos verbales con el objetivo de ofrecer algunas generalidades sobre su comportamiento lingüístico.
\end{abstract}

Palabras clave: juego verbal, acto de habla, patrón rítmico, motivación, cómputo silábico

\begin{abstract}
This paper presents the description of 169 rhyming cases of word play in Mexican Spanish. After adequately characterizing the notion of word play, I point out the relevance of considering these discursive practices from their dimension as speech acts. Subsequently, I offer a descriptive analysis that determines the number of syllables, the rhythmic pattern and the motivation of these cases of rhyming word play, in order to offer some general aspects of their linguistic behavior.
\end{abstract}

Keywords: word play, speech act, rhythmic pattern, motivation, syllabic analysis

\section{INTRODUCCIÓN}

Desde una perspectiva descriptiva de los hechos lingüísticos, el comportamiento verbal de los seres humanos, en cualquiera de sus manifestaciones, debiera proyectarse en un sinfín de vetas de estudio por explorar. De ahí la necesidad de pensar en una lingüística en la que tenga cabida la investigación de cualquiera de las prácticas verbales en las que los grupos humanos asientan sus posibilidades expresivas y per-

'Mi más sincero agradecimiento para Paola Encarnación, Juan Carlos Calvillo y Niktelol Palacios por sus valiosas observaciones y comentarios para llevar a buen término esta investigación. 
filan sus horizontes comunicativos, sin importar el lugar que ocupen en el espectro de estilos, niveles o registros que se vislumbran en una concepción diasistémica de las lenguas (Coseriu, 1981).

A pesar de la irrefutable condición sociohistórica, dialógica y dinámica de nuestros intercambios verbales, buena parte de los modelos teóricos que dominan la lingüística contemporánea se justifican en una perspectiva inmanente y autocontenida de los sistemas lingüísticos humanos que, a pesar de sus alcances, han provocado que se pase por alto o se desatienda el análisis de diversos fenómenos que también forman parte de la realidad concreta de las lenguas.

En vista de ello, me adhiero a la concepción coseriana de que la competencia lingüistica debe entenderse como un saber hablar (Coseriu, 1992 [1988]) en el que cabe distinguir entre la facultad del lenguaje como hecho biológico y el hablar como proceso histórico cuyo desarrollo se funda y se transmite en la sociedad a manera de tradiciones verbales (Lara, 2009; 2012; 2014).

Estas tradiciones se reflejan en un saber hablar que se materializa en prácticas discursivas sustentadas en el eje del discurso repetido (Coseriu, 1977); de modo que la historicidad de la lengua se manifiesta en usos lingüísticos, más o menos convencionalizados, que dotan de validez y sentido a los comportamientos verbales de los individuos en situaciones comunicativas concretas (Oesterreicher, 1997).

De acuerdo con Lara (2009), cabe reconocer, al menos, dos grandes tradiciones en las que nos desenvolvemos en el ir y venir de nuestras interacciones lingüísticas como miembros de una comunidad: las tradiciones verbales cultas y las tradiciones verbales populares.

Las tradiciones cultas «Obedecen a la valoración que hace una sociedad de las funciones de la lengua que traman su vida política, jurídica, cultural y científica» (Lara, 2012: 53); en este sentido, se trata de usos de la lengua que, en el caso del español, se reciben y cultivan a través de la lectura y de la educación escolar.

Las tradiciones populares, en cambio, se gestan en la actividad dialógica de las conversaciones que se establecen entre los miembros de una sociedad en el ámbito cotidiano. Estos modos de expresión se distinguen por su espontaneidad y un arraigo cultural que estimula el fortalecimiento de vínculos sociales y rasgos identitarios. De acuerdo con Lara, estas tradiciones verbales populares «se comunican mediante ciertas técnicas discursivas para el diálogo, para la lírica, para el teatro, para el cine, para el caló, para el albur» (2012: 55).

Teniendo como marco estos supuestos teóricos, en este trabajo presento un análisis descriptivo del cómputo silábico, patrón rítmico y motivación de una serie de juegos verbales con rimas en el español de México, partiendo de su consideración como actos de habla (Austin, 1962; Searle, 1969). 
El trabajo se divide en seis apartados, en el primero, señalo algunos antecedentes importantes para el estudio de este tipo de fenómenos lingüísticos y caracterizo la noción de juego verbal para dejar en claro mis unidades de análisis. En el segundo, realizo un breve recuento del método mediante el cual obtuve los datos con los que trabajé. En el tercero, elaboro una clasificación general de este conjunto de datos como actos de habla tomando como referencia la Guia de Estudios de la Atenuación en los corpus PRESEEA (2014). En el cuarto apartado, presento una descripción detallada del número de sílabas y el patrón rítmico de los datos tomando como base los principios de métrica española desarrollados por Navarro Tomás (1973 y 1975 [1959]), Domínguez Caparrós (1985 y 2014) y Pardo y Pardo (2010). En el quinto apartado, ofrezco un acercamiento a las posibles motivaciones de estos juegos verbales con rimas ciñéndome al plano del signo lingüístico (significante, significado o ambos) que tiene incidencia en su conformación. Por último, apunto algunas consideraciones finales respecto a los hallazgos de esta investigación.

\section{ANTECEDENTES}

Partiendo de la propuesta de Quesada (1999), como juego verbal entenderé la manipulación de los distintos componentes que estructuran un sistema lingüístico con fines lúdicos, mediante el uso de una o más técnicas discursivas. De modo que, de entre las diversas funciones que los hablantes pueden darle a una lengua, existe la práctica de aprovechar, modificar o alterar los patrones formales o semánticos habituales de ciertas estructuras lingüísticas bien arraigadas en una comunidad con el fin de producir un efecto festivo, creativo, ingenioso, atenuador, etcétera ${ }^{1}$. Esta manipulación puede resultar meramente ornamental en términos del significado o de la proposición del mensaje, sin embargo, desde una perspectiva pragmática puede producir o realzar diversos efectos comunicativos (Kabatek, 2015).

El juego verbal se vale de distintas técnicas discursivas que pueden operar en el plano de la expresión, en el plano del contenido o en ambos planos de los signos lingüísticos. Los ejemplos de (1) muestran que para que algunos de estos juegos funcionen resulta necesario que haya una serie de indicios formales que permitan

${ }^{1}$ Verena Thaler (2016) recopila más de una decena de funciones que este tipo de juegos pueden tener, por ejemplo: alcanzar un efecto humorístico, demostrar creatividad y habilidad lingüísticas, provocar el involucramiento emocional del o los interlocutores, atraer la atención del oyente, ridiculizar o avergonzar a alguien, condensar información, establecer lazos de solidaridad, expresar cortesía, salvaguardar la imagen social del hablante, entre otros. 
que el oyente recupere, a partir de la estructura modificada, la forma y el sentido de la estructura original que, al menos en estos casos, son resultado de fórmulas discursivas usuales y bien establecidas en la actividad verbal de los mexicanos:

(1)

a. ¿Qué milanesas hace tiempo que no bisteces? / ¿Qué milagro hace tiempo que no te veia?

La expresión en (1a) presenta una sustitución deliberada de la palabra milagro por milanesas y te veía por bisteces, que, además de tener una similitud formal entre sí que posibilita el juego desde el punto de vista del significante, milanesas y bisteces pertenecen al mismo campo léxico de la CARNE.

b. ¿Qué transistores? / ¿Qué transa?

(1b) donde la expresión ¿Qué transa? como variante de uso popular de los saludos ¡Qué tal? o ¡Cómo te va?, según lo indica el Diccionario del español de México (DEM, 2010: s.v. transa), se sustituye por la voz transistores por la cercanía formal entre ambas unidades léxicas.

\section{c. A Shangai a Sumatra / A chingar a su madre}

En (1c) se aprecia una vez más un proceso de sustitución entre los elementos chingar por Shangai y su madre por Sumatra debido a una similitud estructural entre ambas expresiones. Además, desde el punto de vista del contenido, Shangai y Sumatra comparten el hecho de ser dos topónimos orientales, de un municipio chino en el caso de Shangai y una isla situada en Indonesia para el caso de Sumatra. De igual modo, llama la atención que, desde un punto de vista pragmático, $A$ Shangai a Sumatra tiene una función eufemística y por ende atenuadora, dado el significado de Mandar a alguien a chingar a su madre: Ningunearlo, deshacerse de él, cortarlo (DEM, 2010: s.v. madre).

Si bien en los ejemplos de (1) el juego funciona, sobre todo, en el plano de la expresión del signo, existe una gran diversidad de técnicas discursivas para su formación. Prueba de ello es el interés de algunos investigadores por detectar y describir algunos mecanismos y técnicas recurrentes en la creación de juegos verbales. Lope Blanch (1980) reconoce un esquema general que consiste en el alargamiento 
de una palabra o lexema base mediante la adición de sufijos o pseudosufijos: quintos $\rightarrow$ quintoniles; caro $\rightarrow$ cariñoso; yo $\rightarrow$ Yolanda; Quesada (1999) presenta casos de alteraciones segmentales: es tu recto por es correcto; inversión de segmentos y sílabas: ¿Qué me tacuen? en lugar de ¿Qué me cuenta?; rimas ¿Listo Calixto?; truncamientos ¿Qué me dici-embre? en vez de ¿Qué me dijiste?; entre otros; Lara (2012) reflexiona sobre la dimensión semántica de estos juegos y agrega casos de eufemismos: mamón $\rightarrow$ mamerto; metáforas: la azotea por la cabeza; formaciones neológicas domingo $\rightarrow$ dormingo y apócopes policía $\rightarrow$ poli.

Bastan estos ejemplos para comprender la variedad de recursos lingüísticos que se formalizan en estas expresiones verbales, por lo que es posible aproximarse a ellas desde distintos ángulos descriptivos dependiendo de si se pone el acento en el plano formal o el plano del contenido de estas unidades. Dada esta riqueza de mecanismos lingüísticos, para este trabajo he decidido centrarme exclusivamente en aquellos juegos verbales que se sirven de rimas o formulas rimadas como las que aparecen en (2):
(2)
a. ¿Qué ondita con el pandita?
b. Is barniz, cara de lombriz.
c. El mero mero petatero

\section{MÉTODO DE OBTENCIÓN DE DATOS}

Tanto Lope Blanch (1980), como Quesada (1999) y Lara (2012) reconocen la presencia de fórmulas rimadas como un mecanismo productivo en la construcción de juegos verbales. La rima, como elemento integrante de producciones lingüísticas fuera del ámbito poético, ha sido abordada en función de su papel en la estructura métrica de los refranes (Anscombre, 1999) y de la influencia que ejerce, junto a otros componentes rítmicos como el acento, la pausa y el número de sílabas métricas, en el proceso de fijación de paremias (Frenk, 1961; Bizzarri, 2004; Oddo, 2015) y locuciones (Pla, 2017). Como ya había sido advertido por Morawsky (1927), las fórmulas rimadas del español pueden ser de tipo asonante, consonante o aliterada. De los tres tipos reconocidos por Morawsky, en este trabajo solamente analizaré aquellas expresiones compuestas por rimas consonantes como las que aparecen en (2).

La muestra que recopilé se compone de 169 juegos con rimas consonantes que obtuve de diversas fuentes como obras lexicográficas, páginas de internet, blogs, trabajos de investigación previos, entre otras. En la tabla 1 aparece el número de datos que tomé según las fuentes consultadas: 


\begin{tabular}{|c|c|c|}
\hline Fuente & TIPO DE FUENTE & $\begin{array}{l}\text { NÚMERO DE } \\
\text { DATOS }\end{array}$ \\
\hline $\begin{array}{l}\text { Documentación para el proyecto del Diccionario del español de } \\
\text { México }^{2} \text { (2019) (en adelante DDEM19) }\end{array}$ & Varias & 61 \\
\hline $\begin{array}{l}\text { Boyer, J. (2013). Forma y función de los juegos fónicos en el habla } \\
\text { juvenil de Puebla. [Tesis de maestría]. Canada: Faculté des arts } \\
\text { et sciences, Université de Montréal. (en adelante JB13) }\end{array}$ & Tesis de maestría & 30 \\
\hline $\begin{array}{l}\text { http://expresionateloquequieras.blogspot.mx/2010/02/fra- } \\
\text { ses-nacas.html (2010) (en adelante FN10) }\end{array}$ & Blog & 26 \\
\hline $\begin{array}{l}\text { Guzmán, L. (en proceso de elaboración). Juegos verbales de } \\
\text { afirmación y negación en el español de la Ciudad de México: un } \\
\text { estudio lexicológico. [Tesis de licenciatura]. México: Escuela } \\
\text { Nacional de Antropología e Historia. (en adelante LG) }\end{array}$ & Tesis de licenciatura & 15 \\
\hline $\begin{array}{l}\text { Revista Chilango: Frases que dicen que decimos los chilangos } \\
\text { al saludar (2015) (en adelante RC15) }\end{array}$ & Revista electrónica & 11 \\
\hline El Chilangonario (2012) & Obra lexicográfica & 9 \\
\hline $\begin{array}{l}\text { https://masdemx.com/2016/11/refranes-dichos-mexica- } \\
\text { nos-de-barrio-barriales-calle/ (2016) (en adelante RDM- } \\
\text { BBC16) }\end{array}$ & Página de internet & 5 \\
\hline El Cabulario (2015) & Obra lexicográfica & 4 \\
\hline Lope Blanch (1980) (en adelante LB80) & $\begin{array}{l}\text { Artículo de } \\
\text { investigación }\end{array}$ & 3 \\
\hline El Chingonario (2010) (en adelante $\mathrm{CH} 2010)$ & Obra lexicográfica & 2 \\
\hline $\begin{array}{l}\text { https://marcianosmx.com/diccionario-naco/ (2008) (en } \\
\text { adelante DN08) }\end{array}$ & Página de internet & 1 \\
\hline
\end{tabular}

${ }^{2}$ El equipo lexicográfico del proyecto del Diccionario del español de México (DEM) cuenta con una vasta documentación sobre el vocabulario utilizado en el español mexicano a partir de 1921. Parte de esta documentación es una base de datos sobre tradiciones verbales populares que se ha ido conformando como parte del trabajo lexicográfico que se ha venido elaborando desde 1973. En estos momentos nos encontramos clasificando esta base de datos de juegos verbales con el cuidado que amerita para en el futuro próximo ofrecer un catálogo en el que se especifiquen los principales mecanismos formales y semánticos de estos juegos. Una parte de estos datos proviene de usos que se han registrado a partir de lo que hemos escuchado en la radio y la televisión mexicanas, así como usos que nos han hecho llegar informantes o usuarios del DEM. 


\begin{tabular}{|l|l|l|}
\hline \multicolumn{1}{|c|}{ Fuente } & TIPO DE FUENTE & $\begin{array}{l}\text { NÚMERO DE } \\
\text { DATOS }\end{array}$ \\
\hline $\begin{array}{l}\text { Útily muy ameno vocabulario para entender a los mexicanos } \\
(2011) \text { (en adelante UVM11) }\end{array}$ & Obra lexicográfica & 1 \\
\hline $\begin{array}{l}\text { https://www.chilango.com/chilangonol/lugares-comunes } \\
(2017) \text { (en adelante CHLC17) }\end{array}$ & Revista electrónica & 1 \\
\hline Total & & 169 \\
\hline
\end{tabular}

Tabla 1. Número de juegos verbales con rimas por fuente

Estos 169 juegos verbales fueron tomados de las fuentes que aparecen en la tabla 1. En todas las fuentes consideradas para conformar esta muestra, los juegos aparecen enlistados junto a otros que recurren a diversas técnicas discursivas como las señalados por Lope Blanch (1980) o Lara (2012); no obstante, ninguna de estas fuentes presenta un análisis descriptivo de su estructura rítmica.

Como he venido mencionando, la selección de los datos la determiné con base en el criterio de que se observara la presencia de rimas consonantes en la estructura de estas expresiones lingüísticas. Si bien tomé esta decisión operativa para componer mi corpus de trabajo, me parece importante señalar que estos 169 juegos constituyen o se forman a partir de lo que autores como Zuluaga (1980), Corpas (1996) y Solano (2012), dentro del universo de las unidades fraseológicas (UF), denominan enunciados fraseológicos. En este trabajo, me adscribo a la clasificación de Solano (2012) quien distingue cuatro grandes tipos de $U^{3}{ }^{3}$ y a diferencia de Zuluaga (1980) y Corpas (1996) coloca las paremias fuera de los enunciados fraseológicos4.

${ }^{3}$ La tipología de Solano (2012) distingue entre: a) Sintagmas fraseológicos: colocaciones y locuciones, b) Enunciados fraseológicos: rutinarios, pragmáticos, discursivos y proverbiales, c) Esquemas sintácticos, d) Paremias: refranes, proverbios, frases proverbiales, dialogismos, adagios, apotegmas, máximas.

${ }^{4}$ De acuerdo con Anscombre (2000) las paremias se caracterizan por ser enunciados autónomos, genéricos, sentenciosos, que presentan un bimembrismo semántico y una estructura métrica. Si bien algunas de estas propiedades también se exhiben en los datos que he venido presentado, me parece que es claro que ninguno de los juegos que recopilé para este trabajo enuncian un juicio o una sentencia y muchos de ellos tampoco tienen una estructura bimembre. Basten como ejemplos los siguientes refranes cuyas características difieren de los ejemplos de (3), (4) y (5):

a. A cada capillita le llega su fiestecita: Este refrán suele utilizarse para decir que es importante tener paciencia ya que tarde que temprano las cosas llegarán.

b. Te casaste, te fregaste: Este refrán se utiliza para señalar que asumir un compromiso, como el matrimonio, implica obligaciones y responsabilidades que en ocasiones pueden ser desagradables o molestas.

c. Bueno es el vino, cuando es del fino: Este refrán se utiliza cuando se quieren destacar los beneficios de alguna cosa cuando es de buena calidad. 
De acuerdo con Solano (2012: 122), los enunciados fraseológicos se caracterizan por tener un significado esencialmente pragmático-situacional; por constituir actos de habla ilocutivos o perlocutivos, por lo que su ámbito de uso preferente es la conversación, y por facilitar la interacción comunicativa.

En el conjunto de datos que presento, me parece que cabe hacer las siguientes distinciones:

i. Por un lado, encuentro juegos que toman como núcleo un enunciado fraseológico en el que su carácter lúdico parte de la yuxtaposición o sustitución de una o más unidades léxicas parónimas que, gracias a su similitud formal, permiten que el significado de la expresión original resulte recuperable para el oyente. Cabe señalar que los grados de similitud entre las unidades parónimas son variables. A la par de la sustitución o yuxtaposición de formas parónimas, también se observa la inserción de otros elementos léxicos que permiten el alargamiento del juego. En los siguientes ejemplos resalto en negritas aquellas palabras en las que se presenta la yuxtaposición o sustitución de unidades léxicas parónimas:

\section{(3)}

a. ¿Quépasotes con tamaños zapatotes? (RC15): Se trata de una expresión lúdica que se ha formado a partir de la estructura del saludo ¿Quépasó?

b. Iguanas ranas ( $\mathrm{RC} 15)$ : Es un parónimo de igual en la expresión igual yo con el sentido de 'yo también'.

c. Peralvillo un segundillo (FN10): donde el topónimo Peralvillo se usa como elemento sustitutivo de la palabra pérame en la expresión espérame un segundo.

i. Por el otro, encuentro expresiones lingüísticas donde el enunciado fraseológico inicial sufre un alargamiento mediante la inserción de uno o más elementos léxicos sin que haya yuxtaposición o sustitución de unidades léxicas parónimas:

\section{(4)}

a. ¡Changos morados, chapulines colorados! (DDEM19): En el español de México es común encontrar el uso de la interjección ;Changos! para manifestar sorpresa ante alguna cosa o acontecimiento inesperado o repentino. Este juego verbal toma como base dicha interjección.

\footnotetext{
${ }^{5}$ Peralvillo es el nombre de un barrio de la Ciudad de México de gran tradición histórica ubicado en la colonia Morelos que forma parte de la alcaldía Cuauhtémoc.
} 
b. ¿Qué te pasa, calabaza? (DDEM19): En el español mexicano es común el uso del enunciado fraseológico ¿Qué te pasa? como variante para preguntarle a una persona ¿Qué te sucede?, ¿Qué tienes? ¿ ¿Qué pasó? Nuevamente esta expresión funciona como núcleo para construir esta expresión lúdica mediante la suma del elemento calabaza $a^{6}$.

c. Nel pastel, coronel (DDEM19): En este ejemplo, el adverbio nel como variante de uso popular de no, según lo que consigna el DEM (2010 s.v. nel), funciona como el núcleo de este juego verbal al que se le han agregado los elementos pastel y coronel.

iii. Finalmente, también encuentro enunciados fraseológicos en los que no hay ni yuxtaposición de unidades léxicas parónimas, ni alargamientos mediante la inserción de otros elementos lingüísticos, sino que se trata de expresiones completas cuyo valor lúdico depende del significado composicional de la expresión:

a. Como dijo Mickey Mouse, cada quien para su house (RC15): Se expresa al momento que es hora de irse, despedirse o decir adiós.

b. ¿Coges, fajas o te bajas? (DDEM19): Funciona como una invitación para realizar el acto sexual.

c. Ya comí, ya bebi, ya no me hallo aqui (DDEM19): Se utiliza para despedirse en alguna comida o cena.

En la tabla 2 aparecen los 169 juegos verbales que componen mi base de datos agrupados a partir de las características estructurales recién descritas:

${ }^{6}$ Es importante recordar que, como el resto de los dialectos americanos del español, el español de México es una variante seseante, por lo que la pronunciación de las letras $\langle s\rangle$ y $\langle z\rangle$, así como la $\langle c\rangle$ antes de las vocales /i/o /e/, se pronuncian como /s/. Esta característica del español de México es la que permite que se cumpla la rima consonante en este ejemplo. 
Estructura rítmica y motivación de algunos juegos verbales con rimas en el español de México

\begin{tabular}{|l|c|}
\hline \multicolumn{1}{|c|}{ JUEGOS VERBALES CON RIMAS } & NÚMERO DE CASOS \\
\hline $\begin{array}{l}\text { Con yuxtaposición de unidades parónimas y alargamiento mediante la } \\
\text { inserción de otros elementos léxicos }\end{array}$ & 41 \\
\hline $\begin{array}{l}\text { Sin yuxtaposición de unidades parónimas, pero con alargamientos } \\
\text { mediante la inserción de otros elementos léxicos }\end{array}$ & 81 \\
\hline $\begin{array}{l}\text { Sin yuxtaposición de unidades parónimas ni alargamientos, pero que } \\
\text { funcionan como expresiones completas }\end{array}$ & 47 \\
\hline Total & 169 \\
\hline
\end{tabular}

Tabla 2. Clasificación de los juegos verbales con rimas a partir de sus propiedades estructurales

Una vez presentadas las decisiones metodológicas y las fuentes a partir de las cuales recopilé mi muestra de datos, en los siguientes apartados profundizo en estos 169 juegos verbales con rimas a partir de los siguientes ejes de análisis: el tipo de acto de habla en el que suelen usarse, el número de sílabas y patrón rítmico que los constituye y su motivación lingüística.

\section{ACTOS DE HABLA}

Durante mucho tiempo, buena parte de la teorización lingüística ha estado fundamentada en la propiedad designativa o referencial de las expresiones lingüísticas. De ahí el interés por comprender el funcionamiento de las lenguas en cuanto sistemas para nombrar o describir personas, objetos, propiedades, situaciones o sucesos. Si bien la designación resulta una de las dimensiones de lo que se comunica en el decir (Coseriu, 2001), la naturaleza dialógica del comportamiento verbal de los seres humanos no se limita a la posibilidad de constatar hechos o estados de cosas en el mundo. La teoría de los actos de habla (Austin, 1962; Searle, 1969) ha aportado consideraciones valiosas al destacar una dimensión pragmática de la comunicación.

Como señalé en el apartado anterior, dado que he considerado estos juegos como enunciados fraseológicos, su sentido pragmático depende de situaciones comunicativas concretas, por lo que al funcionar como actos de habla (Zuluaga, 1980; Solano 2012) cabe observar si se utilizan para saludar, despedirse, afirmar algo, ordenar, hacer una petición, etcétera.

Partiendo de esta premisa, decidí etiquetar estos datos a partir de la taxonomía que aparece en la Guia de Estudios de la Atenuación en los corpus PRESEEA (2014). Esta clasificación simplifica la propuesta original de Searle (1969) y distingue los siguientes actos de habla: 


\begin{tabular}{|c|c|c|}
\hline $\begin{array}{l}\text { Tipo de acto } \\
\text { de habla }\end{array}$ & Características & SubClasificación \\
\hline Asertivo & $\begin{array}{l}\text { El hablante afirma o niega algo } \\
\text { con distintos grados de certeza. }\end{array}$ & $\begin{array}{l}\text { Asertivos de opinión (rechazos, disensiones, } \\
\text { protestas). } \\
\text { Asertivos de información (descripciones del } \\
\text { estado factual de la realidad) }\end{array}$ \\
\hline Directivo & $\begin{array}{l}\text { El hablante busca que el oyente } \\
\text { haga algo a futuro. }\end{array}$ & $\begin{array}{l}\text { Directivos en beneficio del hablante (órdenes, } \\
\text { mandatos, preguntas, prohibiciones, solicitu- } \\
\text { des, súplicas). } \\
\text { Directivos en beneficio del oyente (consejos, } \\
\text { sugerencias, advertencias en beneficio del } \\
\text { oyente, propuestas). }\end{array}$ \\
\hline Compromisivo & $\begin{array}{l}\text { El hablante se compromete a rea- } \\
\text { lizar una acción o una conducta } \\
\text { a futuro. }\end{array}$ & Promesas, contratos, ofrecimientos. \\
\hline Expresivo & $\begin{array}{l}\text { El hablante expresa sus senti- } \\
\text { mientos, actitudes o su estado } \\
\text { emocional respecto de algo. }\end{array}$ & $\begin{array}{l}\text { Expresivos de agradecimientos, halagos, } \\
\text { cumplidos. } \\
\text { Expresivos de insultos, recriminaciones, } \\
\text { quejas, lamentos. }\end{array}$ \\
\hline
\end{tabular}

Tabla 3. Taxonomía de actos de habla considerada para el análisis

A partir de la taxonomía de la tabla 3 clasifiqué cada uno de los 169 juegos de mi base de datos. Cabe señalar que se trata de una clasificación general y exploratoria basada en el acto ilocutivo o en la finalidad que tiene el hablante al enunciar estas expresiones. En los ejemplos de (6) presento algunos juegos que se utilizan como actos de habla asertivos, en (7) juegos empleados como actos de habla directivos y en (8) casos de juegos como actos de habla expresivos ${ }^{7}$ :

(6) Asertivos:

a. Sincho, relincho, me monto y te poncho (DDEM19): 'Si' [Asertivo ${ }^{8}$.

b. Nelson dijo Wilson cuando Johnson le pidió la llave Stilson (Chilangonario): 'Nel' o no' [Asertivo].

${ }^{7}$ En este conjunto de datos no encontré ningún caso de actos de habla compromisivos.

${ }^{8} \mathrm{He}$ decidido etiquetar con la marca asertivo todos aquellos juegos que son variantes de los adverbios si y no: Simona la bluserona (LG); Simocho, poncho (FN10); nones, camarones (JB13); nel pastel, coronel (DDEM19).

${ }^{9} \mathrm{El}$ DEM registra el vocablo nel como variante de uso popular para el adverbio no: nel adv (Po- 
c. San seacabuche, panza de buche (LB80): 'Se acabó' [Asertivo de información].

(7) Directivos:

a. Presta pa' la orquesta (JB13): 'Dámelo' [Ordenar].

b. Buzo $0^{10}$, caperuzo (DDEM19): 'Ponte listo o alerta' [Aconsejar a alguien].

c. ¿Ontoy, rentoy? (JB13): ‘¿En dónde estoy?’ [Preguntar algo].

(8) Expresivos:

a. Me late cacahuate (FN10): 'Estar de acuerdo con algo' [Responder o reforzar lo que el interlocutor ha dicho].

b. ¿Qué epazotes con los ejotes? (FN10): ‘¿Qué pasó, cómo estás?' [Saludar]

c. Chifosca mosca (Chingonario): 'Chingada madre' [Expresar enojo, admiración o sorpresa ante algo].

d. Soy la pura verdura (RDMBBC16): 'Soy la pura verga' ${ }^{11}$ [Expresar un autohalago].

Tal y como afirma Searle (1969), al estudiar un acto de habla es importante distinguir entre lo que el hablante quiere comunicar y lo que significa la expresión lingüística que utiliza para hacerlo. De modo que quedarse solamente con el significado de lo que se expresa en la estructura lingüística de los juegos verbales con yuxtaposiciones y alargamientos daría como resultado la articulación de enunciados sin sentido literal y más de un malentendido. En consecuencia, para que estos juegos tengan éxito en términos comunicativos, la intención del hablante debe ser recuperable y reconocible para el oyente, a pesar de la estructura lingüística en la que se basa el juego; por ejemplo:

(9)

a. La interjección ;Qué onda! registrada en el DEM (2010: s.v. onda) como un modo de saludar de carácter informal se toma como base para el juego ¿Qué hongo, jorongo, tepetongo, morongo? (FN10).

pular) No: "Dijeron que iban a venir, pero nel, jalaron para otro lado" (DEM, 2010, s.v. nel).

${ }^{10}$ El DEM documenta el adjetivo buzo con el siguiente significado: adj (Popular) Que es listo o hábil, que está alerta: “Ponte buzo, que ahí viene la policía!” (DEM, 2010, s.v. buzo).

${ }^{11}$ En el español de México, la palabra verga, además del significado de 'pene', también se utiliza para decir que alguien es muy bueno, muy listo, muy astuto. En el DEM se registra la locución Ser, sentirse, etc alguien (muy) verga con el significado de 'Ser o sentirse muy bueno, listo, mejor que los demás' (DEM, 2010, s.v. verga). 
b. La expresión ;Quétransa? que se usa como variante de ‘QQué tal?’ o ‘Cómo te va?' funciona como base para el juego con rimas ¿Qué transa hay en tu pan$z a^{12} ?(\mathrm{FN} 10)$.

En la tabla 4 aparece un conteo final de la clasificación que hice de los datos a partir de la taxonomía de la tabla 3:

\begin{tabular}{|l|l|l|}
\hline $\begin{array}{c}\text { TIPO DE } \\
\text { ACTO DE } \\
\text { HABLA }\end{array}$ & $\begin{array}{c}\text { NÚMERO } \\
\text { DE CASOS }\end{array}$ & \multicolumn{1}{c|}{ SUBCLASIFICACIÓN } \\
\hline Expresivo & 91 & $\begin{array}{l}\text { Responder o reforzar lo que ha sido dicho por el interlocutor: } 36 \text { casos } \\
\text { Saludar: } 17 \text { casos } \\
\text { Despedirse: } 14 \text { casos } \\
\text { Manifestar sorpresa, admiración o enojo ante algo: } 9 \text { casos } \\
\text { Autohalagarse: } 4 \text { casos } \\
\text { Insultar: } 2 \text { casos } \\
\text { Burlarse: } 3 \text { casos } \\
\text { Señalar que algo representa poca dificultad o esfuerzo: } 2 \text { casos } \\
\text { Quejarse: } 2 \text { caso } \\
\text { Prevenir a alguien: } 1 \text { caso } \\
\text { Ofrecer algo: } 1 \text { caso }\end{array}$ \\
\hline Directivo & 43 & $\begin{array}{l}\text { Aconsejar, tranquilizar o hacerle una propuesta a alguien: } 31 \text { casos } \\
\text { Preguntar algo: } 5 \text { casos } \\
\text { Ordenar: } 5 \text { casos } \\
\text { Invitar: } 2 \text { casos }\end{array}$ \\
\hline Asertivo & 35 & $\begin{array}{l}\text { Asertivo de información: } 16 \text { casos } \\
\text { Asertivo sí/no: } 18 \text { casos } \\
\text { Asertivo de opinión: } 1 \text { caso }\end{array}$ \\
\hline Total & 169 & \\
\hline
\end{tabular}

Tabla 4. Clasificación de los datos por acto de habla

La tabla 4 muestra que los actos de habla expresivos son los que más aparecen en mi muestra de trabajo. Desde la perspectiva de las funciones del signo lingüístico, tal y como las entiende Bühler (1934), llama la atención que sea la función sintomática la que más presencia tiene en este conjunto de datos. De toda esta serie de actos expresivos, los más recurrentes son los que se utilizan para responder o reforzar lo que ha sido dicho por el interlocutor (36 casos); los que se usan para saludar (17 casos) o despedirse (14 casos) y, también, los que se enuncian para manifestar sorpresa, admiración o enojo ante algún suceso o situación ( 9 casos). Una posible explicación de la recurrencia de estos subtipos de actos de habla expresivos es que se trata de ex-

\footnotetext{
${ }^{12}$ Otro ejemplo más del seseo característico del español mexicano.
} 
presiones que forman parte de actos comunicativos cotidianos y rutinarios en la vida social. Por ejemplo, los saludos, las despedidas y las manifestaciones de refuerzo ante lo enunciado previamente por el interlocutor son sumamente comunes en nuestras interacciones comunicativas diarias; sin embargo, su formalización mediante este tipo de juegos da lugar a una reacción de simpatía, solidaridad, cercanía y sentimiento popular. En el caso de los actos de habla directivos, los que más se repiten son los que se emplean para aconsejar o hacerle una propuesta a alguien (31 casos), enunciar una pregunta ( 5 casos) y dar una orden ( 5 casos). Por último, en el caso de los actos de habla asertivos, donde predomina la función referencial del signo lingüístico, se observa la prevalencia de actos de habla asertivos de información (16 casos) y actos de habla asertivos en los que se afirma o se niega algo (18 casos). A diferencia de los actos de habla expresivos y directivos, los actos de habla asertivos permiten constatar o hacer referencia a algún estado de cosas o hechos en el mundo real o en un mundo imaginario a los que el hablante apela. Sin duda alguna, bien cabría ampliar esta muestra de datos y observar si efectivamente, desde la perspectiva de los actos habla, son los actos expresivos los que mayor incidencia tienen en este tipo de juegos verbales.

\section{CÓMPUTO SILÁBICO Y PATRÓN RÍTMICO}

El hecho de que estos juegos verbales se formalicen mediante rimas consonantes refleja la preeminencia de la forma como condición fundamental en la construcción de los signos lingüísticos (Hjelmlsev, 1971 [1943]). De manera que las posibilidades estructurales de una lengua, cimentadas en la repetición de patrones silábicos, morfológicos, sintácticos o discursivos, constituyen esa forma histórica que nos antecede como hablantes al momento de adquirir nuestra lengua materna (Lara, 2006). Por consiguiente, las formas métricas que se cultivan en una lengua a lo largo del tiempo, dependen en buena medida de sus propiedades prosódicas particulares (Domínguez, 2016); aspecto que se manifiesta en las técnicas discursivas que se emplean en la producción de las expresiones lúdicas bajo estudio.

Para analizar la estructura rítmica de los 169 juegos verbales de mi muestra, parto de una noción amplia de ritmo, que, siguiendo a Pla (2017), a partir de los planteamientos de Domínguez (2014), debe entenderse como: «la percepción producida por la agrupación de los acentos de un enunciado en intervalos temporales regulares, por un lado, y la distribución de los acentos y su organización en estructuras rítmicas» (Pla, 2017: 90). Esta concepción amplia permite abordar estructuras lingüísticas que, a pesar de no formar parte de una composición poética desde un 
punto de vista tradicional, cuentan con una organización rítmica en la que es posible observar la presencia de un numero de sílabas preciso, una distribución regular de los acentos y el uso de rimas (Pardo y Pardo, 2010).

De manera que, contrario a la idea de que un verso aislado solo puede ser considerado como tal si forma parte de una estrofa, como unidad superior (Quilis, 2007 [1984), retomo la postura de Pardo (2004), quien apunta la pertinencia de considerar un verso aislado, un verso solo y un verso-poema como unidad rítmica; concepción que abre el espectro para abordar las cualidades rítmicas de estructuras lingüísticas como los refranes (Domínguez, 1985; Anscombre, 2012; Oddo, 2015), las locuciones (Pla, 2017) y, en este caso, los juegos verbales.

Partiendo de este punto de vista, el primer acercamiento que tuve hacia los datos fue clasificarlos según su número de sílabas para establecer si se trataba de versos simples o compuestos ${ }^{13}$.

La tabla 5 muestra el número de juegos verbales que constan de versos simples y compuestos:

\begin{tabular}{|l|l|}
\hline Juegos verbales en verso simple & 134 casos \\
\hline Juegos verbales en verso compuesto & 35 casos \\
\hline Total & $\mathbf{1 6 9}$ casos \\
\hline
\end{tabular}

Tabla 5. Juegos verbales en verso simple y en verso compuesto

En (10) presento tres ejemplos de juegos verbales en verso simple y en (11) tres ejemplos de juegos verbales en verso compuesto ${ }^{14}$ :

a. Chido one, tehuacán (FN10).

chi-do-uán-te-hua-cán.

[Verso simple que consta de siete sílabas].

b. ¿Qué Pachuca por Toluca? (DDEM19).

qué-pa-chu-ca-por-to-lu-ca.

[Verso simple que consta de ocho sílabas].

${ }^{13}$ De acuerdo con Quilis (2007 [1984]: 54-55), los versos pueden ser simples cuando constan de un solo verso de entre una y once sílabas métricas o compuestos (o con pausa interna) cuando constan de doce o más sílabas. Los versos compuestos se dividen en dos o más versos simples separados por una cesura lo que, desde la perspectiva de la métrica, obliga a tratarlos como versos independientes; de manera que la cesura impide la sinalefa y obliga a reiniciar el conteo.

${ }^{14}$ En negritas resalto las sílabas acentuadas, con subrayado marco las sinalefas y con la barra indico la cesura en los casos de juegos verbales compuestos. 
c. Ya tienespeluche en el estuche (FN10).

ya-tie-nes-pe-lu-cheen-el-es-tu-che.

[Verso simple consta de diez sílabas].

(11)

a. Como dijo el gran queso, al rato regreso (Chilangonario).

co-mo-di-joel-gran-que-so / al-ra-to-re-gre-so.

[Verso compuesto que consta de trece sílabas].

b. Bambi es un venado y Tambor su valedor (DDEM19).

bam-bies-un-ve-na-do / y-tam-bor-su-va-le-dor.

[Verso compuesto que consta de catorce sílabas].

c. Me extraña que siendo araña no se sepa ya esa maña (DDEM19).

meex-tra-ña-que-sien-doa-ra-ña / no-se-se-pa-yạe-sa-ma-ña.

[Verso compuesto que consta de dieciséis sílabas].

Como he venido señalando, los juegos verbales que tomé en cuenta para este estudio están compuestos por rimas consonantes. Dado que la mayoría de estos datos presenta una estructura de verso simple, estos juegos se caracterizan por presentar rima interna ${ }^{15}$. Como se muestra en (12), la rima interna de estos juegos verbales en verso simple se caracteriza por repetir los fonemas o las sílabas rimantes de algunas de las palabras que los conforman:

a. Te conozco, Orozco (FN10).

b. Aotra cosa mariposa (DDEM19).

c. Soy la neta del planeta (DDEM19).

d. Aja aja la baraja (DDEM19).

El mismo esquema se observa en la composición de los juegos verbales compuestos que constan de doce o más sílabas:

a. ¿Qué Honduras con las verduras / que andan bajas las temperaturas? (RC15).

b. Chido, Liro, Ramiro / y el vampiro, Clodomiro (FN10).

c. Vaya, vaya Tacubaya, / si no conoce mejor no vaya (DDEM19).

${ }^{15}$ Tal y como señalan Baher (1970: 73) y Domínguez (1985: 134), la rima interna es aquella que se da en el interior del verso. 


\subsection{Cómputo silábico en los datos}

En cuanto al cómputo silábico de los datos, realicé el conteo correspondiente a partir del número de sílabas métricas que poseen. La tabla 6 muestra los resultados finales para el caso de los juegos verbales en verso simple:

\begin{tabular}{|c|c|c|c|}
\hline \multirow{9}{*}{$\begin{array}{l}\text { Juegos verbales en } \\
\text { verso simple }\end{array}$} & $\begin{array}{c}\text { NÚMERO DE SÍLABAS } \\
\text { MÉTRICAS }\end{array}$ & NúMERo de CASOS & Porcentaje \\
\hline & 4 & 4 & $2,99 \%$ \\
\hline & 5 & 28 & $20,9 \%$ \\
\hline & 6 & 22 & $16,42 \%$ \\
\hline & 7 & 21 & $15,67 \%$ \\
\hline & 8 & 47 & $35,06 \%$ \\
\hline & 9 & 6 & $4,48 \%$ \\
\hline & 10 & 3 & $2,24 \%$ \\
\hline & 11 & 3 & $2,24 \%$ \\
\hline \multicolumn{3}{|r|}{ Total: 134} & $100 \%$ \\
\hline
\end{tabular}

Tabla 6. Número de sílabas métricas en juegos verbales simples

La tabla 6 muestra que los juegos verbales de cinco, seis, siete y ocho sílabas métricas son los únicos que superan la veintena de casos y conforman el 88,05\% de los juegos verbales en verso simple. Quilis señala que los versos de arte menor, es decir, los que tienen entre dos y ocho sílabas métricas, son sumamente frecuentes en la versificación española por su agilidad; gracias a la cual son «muy aptos para composiciones poéticas ligeras» (Quilis, 2007 [1984]: 55). De igual modo, llama la atención el predominio de juegos con ocho sílabas métricas, lo que confirma la predilección por este metro tanto en la tradición literaria hispánica, como en el modo de distribución de los elementos en el plano discursivo. Navarro Tomás señala que «Un rasgo significativo consiste en el hecho de que el metro octosílabo, tan antiguo, popular y permanente en español, coincida precisamente con la medida del grupo fónico más frecuente en la ordinaria elocución enunciativa de la lengua» (1973: 8).

En relación con lo anterior, Domínguez agrega que el verso octosílabo es el más usado en la literatura hispánica, gracias a que «Se adapta a cualquier asunto y mantiene un extraordinario vigor, especialmente en la poesía popular» (1985: 102).

La tabla 7 indica el número de juegos verbales en verso compuesto a partir de sus sílabas métricas: 
Estructura ritmica y motivación de algunos juegos verbales con rimas en el español de México

\begin{tabular}{|c|c|c|c|c|}
\hline \multirow{9}{*}{$\begin{array}{l}\text { JUEGOS VERBALES EN } \\
\text { VERSO COMPUESTO }\end{array}$} & $\begin{array}{c}\text { Número de sílabas } \\
\text { métricas }\end{array}$ & $\begin{array}{l}\text { Número de sílabas } \\
\text { por hemistiquio }\end{array}$ & $\begin{array}{l}\text { Número de } \\
\text { casos }\end{array}$ & Porcentaje \\
\hline & 12 & $\begin{array}{l}6 \text { y } 6: 3 \text { casos } \\
5 \text { y } 7: 1 \text { caso } \\
4 \text { y } 8: 1 \text { caso } \\
8 \text { y } 4: 1 \text { caso }\end{array}$ & 6 & $17,14 \%$ \\
\hline & 13 & $\begin{array}{l}8 \text { y } 5: 2 \text { casos } \\
7 \text { y } 6: 2 \text { casos } \\
6 \text { y } 7: 1 \text { caso }\end{array}$ & 5 & $14,29 \%$ \\
\hline & 14 & $\begin{array}{l}6 \text { y } 8: 2 \text { casos } \\
8 \text { y } 6: 1 \text { caso } \\
5 \text { y } 9: 1 \text { caso }\end{array}$ & 4 & $11,43 \%$ \\
\hline & 15 & $\begin{array}{l}7 \text { y } 8: 4 \text { casos } \\
6 \text { y } 9: 1 \text { caso }\end{array}$ & 5 & $14,29 \%$ \\
\hline & 16 & $\begin{array}{l}8 \text { y } 8: 8 \text { casos } \\
7 \text { y } 9: 1 \text { caso }\end{array}$ & 9 & $25,71 \%$ \\
\hline & 17 & \begin{tabular}{|l}
8 y $9: 1$ caso \\
5,6 y $6: 1$ caso
\end{tabular} & 2 & $5,71 \%$ \\
\hline & 18 & $\begin{array}{l}8 \text { y } 10: 2 \text { casos } \\
3,4 \text { y } 8: 1 \text { caso }\end{array}$ & 3 & $8,57 \%$ \\
\hline & 20 & $5,5,5$, y $5: 1$ caso & 1 & $2,86 \%$ \\
\hline & & & Total: 35 & $100 \%$ \\
\hline
\end{tabular}

Tabla 7. Número de silabas métricas en juegos verbales compuestos

Para el caso de los juegos en verso compuesto, además de los hexadecasílabos, con nueve casos, destacan los dodecasílabos y tridecasílabos con seis y cinco casos respectivamente. De los nueve hexadecasílabos de la muestra, ocho están compuestos por dos versos octosílabos; manifestación, una vez más, de su importancia como grupo fónico mínimo de la lengua y patrón métrico fundamental de la poesía popular (Quilis, 2007 [1984]: 65), valgan como ejemplos:

(14)

a. Este osito de peluche ya se va para su estuche (FN10).

es-teo-si-to-de-pe-lu-che / ya-se-va-pa-ra-sues-tu-che.

[octosílabo + octosílabo].

b. Cámara pivote y rin, Mickey, Pluto y Tribilín (DDEM19).

cá-ma-ra-pi-vo-tey-rin / mic-key-plu-toy-tri-bi-lín

[octosílabo + octosílabo]. 
c. iAy, chibuabua, cuánto apache, cuánto indio sin huarache! (DDEM19). ay-chi-hua-hua-cuán-toa-pa-che / cuán-to-in-dio-sin-hua-ra-che. [octosílabo + octosílabo].

\subsection{Patrón rítmico en los datos}

De acuerdo con el modelo musical de Navarro Tomás (1973), el ritmo y la cláusula se estructuran a partir de una sílaba acentuada, de modo que solamente puede haber cláusulas dactílicas y trocaicas. Navarro Tomás (1973: 14) distingue:

i. El ritmo trocaico compuesto por una sílaba tónica y otra átona como en:

a. Escupe, Lupe (DDEM19).

es-cu-pe-lu-pe.

[Pentasílabo trocaico con acentos en la segunda y cuarta sílabas].

b. ¿Cómo ves, Inés? (LG).

có-mo-ves-i-nés.

[Hexasílabo trocaico con acentos en primera, tercera y quinta].

ii. El ritmo dactílico compuesto por una sílaba tónica y dos átonas como en:

a. Hola crayola (DDEM19).

ho-la-cra-yo-la.

[Pentasílabo dactílico].

b. Ya vas, Barrabás (LG).

ya-vas-ba-rra-bás.

[Hexasílabo dactílico).

iii. A estos dos ritmos básicos, Navarro Tomás agrega un tercero que es una combinación trocaica y dactílica a la que denomina ritmo mixto:

a. Ya estáspeinado pa'trás (LG).

yạes-tás-pei-na-do-pa-tras.

[Octosílabo mixto con acentos en la segunda, cuarta y séptima sílabas]. 


\section{b. Yuppi, yuppi el perrito Snoopy (DDEM19).}

yu-ppi-yu-ppiel-pe-rri-toes-noo-py.

[Eneasílabo mixto con acentos en la primera, tercera, sexta y octava sílabas].

\subsubsection{Patrón rítmico en los juegos verbales en verso simple}

A partir de esta propuesta, en la tabla 8 muestro el número de juegos verbales con ritmo trocaico, dactílico y mixto que encuentro en los juegos en verso simple:

\begin{tabular}{|c|c|c|c|}
\hline $\begin{array}{l}\text { NÚMERO DE CASOS DE JUE- } \\
\text { GOS VERBALES EN VERSO } \\
\text { SIMPLE }\end{array}$ & $\begin{array}{c}\text { JUEGOS VERBALES } \\
\text { CON RITMO } \\
\text { TROCAICO }\end{array}$ & $\begin{array}{l}\text { JUEGOS VERBALES } \\
\text { CON RITMO } \\
\text { DACTÍLICO }\end{array}$ & $\begin{array}{l}\text { JUEGOS VERBA- } \\
\text { LES CON RITMO } \\
\text { MIXTO }\end{array}$ \\
\hline 4 tetrasílabos & 4 casos & $\mathrm{NA}^{16}$ & $\mathrm{NA}$ \\
\hline 28 pentasílabos & 17 casos & 11 casos & NA \\
\hline 22 hexasílabos & 13 casos & 9 casos & NA \\
\hline 21 heptasílabos & 12 casos & 7 casos & 2 casos \\
\hline 47 octosílabos & 33 casos & 0 & 14 casos \\
\hline 6 eneasílabos & 0 & 0 & 6 casos \\
\hline 3 decasílabos & 0 & 1 caso & 2 casos \\
\hline 3 endecasílabos $^{17}$ & NA & 1 caso & NA \\
\hline Total: 134 casos & 79 casos & 29 casos & 24 casos \\
\hline Porcentaje: $100 \%^{18}$ & $58,96 \%$ & $21,64 \%$ & $17,91 \%$ \\
\hline
\end{tabular}

Tabla 8. Patrón rítmico de juegos verbales en verso simple

La tabla 8 muestra el predominio de juegos verbales con ritmo trocaico. Esto se ajusta a las características del propio vocabulario de la lengua española que, según la posición del acento, se compone en su mayoría, de palabras graves o llanas ${ }^{19}$. Incluso

\footnotetext{
${ }^{16}$ No aplica
}

${ }^{17}$ Los dos endecasílabos restantes, a partir de la clasificación de Navarro Tomás (1975[1959]: 51-54), corresponden a un endecasílabo heroico con acentos en la segunda, sexta y décima sílabas y un endecasílabo galaico antiguo con acentos en la quinta y décima sílabas.

${ }^{18}$ El 1,49\% faltante para el $100 \%$ corresponde a los dos endecasílabos de la nota 17

${ }^{19}$ De acuerdo con Quilis (2007 [1984]: 27), el vocabulario de la lengua española consta de un $17,68 \%$ de palabras agudas, $79,50 \%$ de palabras graves y 2,76\% de palabras esdrújulas. 
para el caso de los juegos pentasílabos, hexasílabos, heptasílabos y octosílabos, que corresponden a los patrones métricos más recurrentes en los datos, el ritmo trocaico es el que mayor preeminencia tiene.

A continuación, presento algunos ejemplos de juegos verbales pentasílabos, hexasílabos, heptasílabos y octosílabos trocaicos, dactílicos y mixtos:

(18) Pentasílabos trocaicos con acentos en la segunda y cuarta sílabas:

a. Of course my horse (Chilangonario).

of-course-my-horse.

b. Bien dicho, bicho (JB13).

bien-di-cho-bi-cho.

c. ¡Clarines nines! (JB13).

cal-ri-nes-ni-nes.

(19) Pentasílabos dactílicos con acentos en la primera y cuarta sílabas:

a. Leve la nieve (DDEM19).

le-ve-la-nie-ve.

b. Obvio, microbio (DDEM19).

ob-vio-mi-cro-bio.

c. Vásquez Velásquez (JB13).

vás-quez-ve-lás-quez.

(20) Hexasílabos trocaicos con acentos en tercera y quinta sílabas:

a. Segurolas bolas (LG).

se-gu-ro-las-bo-las.

b. ¿Me comprendes Méndez? (JB13).

me-com-pren-des-mén-dez.

c. Me retacho, Tacho (JB13).

me-re-ta-cho-ta-cho.

(21) Hexasílabos dactílicos con acentos en segunda y quinta sílabas:

a. Al tiro vampiro (DDEM19).

al-ti-ro-vam-pi-ro.

b. Ta' gacho, garnacho (FN10).

ta-ga-cho-gar-na-cho.

c. No hay prisa, Marisa (DDEM19).

nohay-pri-sa-ma-ri-sa. 
(22) Heptasílabos trocaicos con acentos en segunda, cuarta y sexta sílabas:

a. ¿Quépedo? Dijo Alfredo (RC15).

qué-pe-do-di-joal-fre-do.

b. Macizo contra el piso (DDEM19).

ma-ci-zo-con-trael-pi-so.

c. ¿Qué transa hay en tu panza? (FN10).

qué-tran-zahay-en-tu-pan-za.

(23) Heptasílabos dactílicos con acentos primera, tercera y sexta sílabas:

a. Chido one, Tehuacán (FN10).

chi-do-uán-te-hua-cán.

b. Nel pastel coronel (DDEM19).

nel-pas-tel-co-ro-nel.

c. Is barniz tanguarniz (LB80).

is-bar-niz-ta-guar-niz.

(24) Heptasílabos mixtos con acentos en primera y sexta sílabas:

a. Neta la patineta (LB13).

ne-ta-la-pa-ti-ne-ta.

b. Arre con la que barre (DDEM19).

a-rre-con-la-que-ba-rre.

(25) Octosílabos trocaicos con acentos en primera, tercera, quinta y séptima sílabas y en primera, tercera y séptima sílabas:

a. No te azotes que hay chayotes (DDEM19).

no-tea-zo-tes-quehay-cha-yo-tes.

b. Leve, nueve, llueve nieve (LB13).

le-ve-nue-ve-llue-ve-nie-ve.

c. Achis, piachis, los mariachis (DDEM19).

a-chis-pia-chis-los-ma-ria-chis.

(26) Octosílabo mixto con acentos en segunda, cuarta y séptima sílabas.

a. Matanga dijo la changa (DDEM19).

ma-tan-ga-di-jo-la-chan-ga.

b. Sin pena sobre la arena (DDEM19).

sin-pe-na-so-bre-laa-re-na.

c. Jazz 'tás peinado pa'l thrash (JB13).

jazz-tás-pei-na-do-pal-thrash. 


\subsubsection{Patrón ritmico en los juegos verbales en verso compuesto}

En cuanto al patrón rítmico de los 35 juegos verbales en verso compuesto de mi muestra, hay casos que constan de dos o más versos simples donde ambos presentan un ritmo trocaico como los ejemplos de (27); casos en los que ambos versos simples tienen un ritmo dactílico como los ejemplos de (28); y casos que se dan mediante la combinación de un verso simple con ritmo trocaico, dactílico o mixto y otro verso simple con un ritmo distinto al primero, en (29) aparecen casos con esta estructura combinada:

(27) Juegos verbales en verso compuesto con ritmo trocaico:

a. Como dijo el Santo Papa: chin, chin, Jalapa (FN10).

co-mo-di-joel-san-to-pa-pa / chin-chin-ja-la-pa.

[Tridecasílabo: octosílabo trocaico + pentasílabo trocaico].

b. Tan caro que es tragar pa' tener que irlo a tirar (FN10).

tan-ca-ro-quees-tra-gar / pa-te-ner-queir-loa-ti-rar.

[Pentadecasílabo: heptasílabo trocaico + octasílabo trocaico].

(28) Juegos verbales en verso compuesto con ritmo dactílico:

a. Relaja la raja, te empino el pepino (DDEM19).

re-la-ja-la-ra-ja / teem-pi-noel-pe-pi-no.

[Dodecasilabo: hexasílabo dactílico + hexasílabo dactílico].

b. Pelón, pelonete, cabeza de cuete. (JB13).

pe-lón-pe-lo-ne-te / ca-be-za-de-cue-te.

[Dodecasilabo: hexasílabo dactílico + hexasílabo dactílico].

(29) Juegos verbales en verso compuesto con estructura combinada:

a. Alguien abrió un cajón y yo me voy pámi cantón (FN10).

al-guien-a-brióun-ca-jón / y-yo-me-voy-pa-mi-can-tón.

[Hexadecasílabo: heptasílabo mixto + eneasílabo trocaico].

b. Disfruta la fruta mientras dura la verdura (RDMBBC16).

dis-fru-ta-la-fru-ta / mien-tras-du-ra-la-ver-du-ra.

[Alejandrino: hexasílabo dactílico + octosílabo trocaico].

En la tabla 9 presento una síntesis del comportamiento rítmico de los juegos verbales en verso compuesto: 
Estructura ritmica y motivación de algunos juegos verbales con rimas en el español de México

\begin{tabular}{|l|l|l|l|}
\hline $\begin{array}{c}\text { NÚMERO DE CASOS DE JUE- } \\
\text { GOS VER BALES EN VERSO } \\
\text { COMPUESTO }\end{array}$ & $\begin{array}{c}\text { JUEG OS VERBALES } \\
\text { CON RITMO TRO- } \\
\text { CAICO }\end{array}$ & $\begin{array}{c}\text { JUEG OS VERBALES } \\
\text { CON RITMO } \\
\text { DACTÍLICO }\end{array}$ & $\begin{array}{c}\text { JUEG OS VER BA- } \\
\text { LES CON RITMO } \\
\text { MIXTO }\end{array}$ \\
\hline 6 dodecasílabos & 2 casos & 4 casos & 0 casos \\
\hline 5 tridecasílabos & 2 casos & 1 caso & 2 casos \\
\hline 4 alejandrinos & 1 casos & 0 & 3 casos \\
\hline 5 pentadecasílabos & 2 casos & 1 caso & 2 casos \\
\hline 9 hexadecasílabos & 5 casos & 0 casos & 4 casos \\
\hline 2 heptadecasílabos & 1 caso & 0 casos & 1 caso \\
\hline 3 octodecasílabos & 1 caso & 0 casos & 2 casos \\
\hline 1 de veinte sílabas & 0 casos & 1 caso & 0 casos \\
\hline Total: 35 casos & 14 casos & 7 casos & 14 casos \\
\hline Porcentaje: $100 \%$ & $40 \%$ & $20 \%$ & $40 \%$ \\
\hline
\end{tabular}

Tabla 9. Patrón rítmico de juegos verbales en verso compuesto

Los resultados de la tabla 9 reflejan el predominio del ritmo trocaico en los juegos verbales en verso compuesto. Esto replica el comportamiento observado en los juegos en verso simple, lo que refuerza la observación de que la lengua española tiene una tendencia hacia el ritmo trocaico.

\section{MOTIVACIÓN}

Pensar en el vínculo que mantienen el significante, el significado y los objetos en el mundo en los procesos de la significación verbal ha desatado el interés por examinar en qué medida los signos lingüísticos se encuentran motivados por factores internos o externos a las lenguas humanas. Es por demás conocida la concepción saussureana de establecer la arbitrariedad del signo como principio general de la ciencia del lenguaje, cuyo efecto inmediato anula todo dejo de consustancialidad en la relación entre significante y significado (Saussure, 1972 [1916]). A pesar de este principio, el mismo Saussure no deja de reconocer la existencia de signos relativamente motivados, como los derivados o los compuestos morfológicos en el nivel léxico, lo que nos lleva de vuelta a preguntarnos por qué las unidades lingüísticas presentan la forma que tienen y significan lo que significan.

A partir del vínculo entre significante y significado, como unidades de naturaleza lingüística y abstracta, y su relación con los referentes en el mundo, comparto lo 
observado por Engler (1964) y Guiraud (1975 [1955]), de que, en principio, cabe hacer la distinción entre motivación ontológica o referencial, que resulta del nexo entre una expresión lingüística y la cosa designada, y motivación intralingüistica o endoglótica que depende de las características propias que cada sistema lingüístico emplea para la comunicación.

Es precisamente esta motivación intralingüística la que me interesa abordar en este apartado, ya que como he venido señalando, los hablantes de cada lengua somos herederos de una forma histórica que nos permite generar una infinidad de unidades y expresiones lingüísticas siempre y cuando se ajusten a las posibilidades combinatorias y estructurales que la constituyen (Taylor, 2006). De modo que, si bien la relación entre significante y significado resulta arbitraria como señalaba Saussure, se trata de una arbitrariedad relativa o controlada, ya que cualquier expresión lingüística se encuentra limitada y motivada por las relaciones sintagmáticas y paradigmáticas distintivas y significativas que subyacen a su enunciación. Esta motivación intralingüística puede advertirse en cualquier nivel de análisis lingüístico ${ }^{20}$. De ahí que, del diálogo entre arbitrariedad y motivación, toda unidad lingüística deba acoplarse a ciertos patrones combinatorios que legitimen su pertinencia y pertenencia a una lengua.

Tomando estas observaciones como base, considero que en el conjunto de datos que he venido presentado hay juegos en los que la motivación actúa solamente en el plano de la expresión mediante la técnica discursiva de la rima consonante como los ejemplos de (30):

\section{(30)}

a. Me canso, ganso (DDEM19).

b. Me extraña araña (JB13).

c. Nones camarones (JB13).

d. Okey, maguey (LG).

e. Seacabuchi, pie de tuchi (DDEM19).

f. Al rato, vato (JB13).

En la serie de ejemplos de (30) se observa que el juego surge solamente a partir de la similitud formal que permite la rima consonante entre late y chocolate; extraña y arana; nones y camarones; okey y maguey; seacabuchi y tuchi; y rato y vato.

Sin embargo, hay varios casos en los que resulta claro que hay elementos del plano de la expresión y del contenido que intervienen en el resultado formal e interpretativo del juego:

\footnotetext{
${ }^{20}$ Fonético, fonológico, morfológico, sintáctico, semántico, etcétera.
} 
(31)

a. ¿Quépasión hay en tu corazón? (FN10).

b. Ahi la vemos y planchemos (Chilangonario).

c. Ya comi, ya bebi, ya no me hallo aqui (DDEM19).

En (31a) además de que se puede recuperar la intención del hablante para saludar mediante la yuxtaposición entre ¿Qué pasó? y ¿Quépasión?, así como de la rima entre el vocablo pasión y corazón, el juego en su totalidad tiene un significado composicional en el que se destaca el papel del corazón como el centro de las pasiones y emociones humanas.

En (31b), además de la rima entre vemos y planchemos, se produce una ambigüedad fónica entre la expresión abi la vemos que se utiliza en el español mexicano como una fórmula para despedirse y lavemos como la conjugación de la primera persona de presente de subjuntivo del verbo lavar, lo que permite la lectura composicional entre dos actividades características del quehacer doméstico como lo son el lavado y el planchado.

En (31c) a la par de la rima entre comí, bebi y aquí, se trata de un dicho con significado composicional que se utiliza para despedirse de algún lugar después de comer y beber.

En la tabla 10 aparece el número de juegos verbales de mi muestra que emplean mecanismos que apelan solamente al plano de la expresión del signo lingüístico y aquellos en los que intervienen tanto del plano de la expresión como del plano del contenido.

\begin{tabular}{|l|c|c|}
\hline $\begin{array}{l}\text { Juegos verbales que operan solamente en el plano del } \\
\text { significante del signo lingüístico }\end{array}$ & 93 casos & $55,03 \%$ \\
\hline $\begin{array}{l}\text { Juegos verbales que operan tanto en el significante como } \\
\text { en el significado del signo lingüístico }\end{array}$ & 76 casos & $44,97 \%$ \\
\hline Total: 169 casos & $100 \%$ \\
\hline
\end{tabular}

Tabla 10. Plano del signo lingüístico en la que operan los juegos verbales

La tabla 10 muestra que hay más de casos en los que el juego verbal actúa solamente en el plano de la expresión del signo lingüístico mediante el empleo de la técnica discursiva de la rima consonante, no obstante, también hay un buen número de casos en los que el juego apela a ambas caras del signo a través de otras técnicas discursivas.

Para finalizar con este apartado, presento algunos ejemplos de las técnicas discursivas que observo en el subconjunto de los datos en los que el juego verbal 
interviene tanto en el plano de la expresión como en el plano del contenido. Es importante adelantar que esta serie de técnicas discursivas no son excluyentes entre sí, pues al analizar cada juego por separado, y desde distintos niveles de descripción lingüística, no es extraño encontrar más de una de las técnicas que presento en un mismo dato. Observaciones como esta reflejan la complejidad y el ingenio que hay detrás de estas expresiones de carácter lúdico.

\subsection{Eufemismos mediante la yuxtaposición de formas parónimas}

En este subconjunto de datos, donde el juego se forma mediante la explotación tanto de aspectos formales como semánticos, encuentro una técnica discursiva en la que la yuxtaposición de formas parónimas se genera a partir de un eufemismo, que a su vez viene motivado por el influjo de la rima:

\section{(32)}

a. verga por verdura en el juego iSoy la pura verdura! (RDMBBC16), cuyo sentido es señalar que el hablante es muy bueno, muy listo, muy astuto para algo.

b. Arroz o más mole o chile para el guacamole (Cabulario), donde las palabras arroz, mole, chile y guacamole pertenecen al campo léxico de la comida, y la palabra chile es un eufemismo de chingón ya que toda esta expresión se yuxtapone a así o más chingón. Por ende, este juego tiene una doble lectura, la que se recupera al reconocer que se trata de una sustitución y la que se genera de manera composicional en la que solamente se habla de una serie de platillos o alimentos comunes en la tradición culinaria mexicana.

c. Ya tienespeluche en el estuche (FN10), en donde la palabra peluche sustituye a la palabra pelo para señalar que un individuo ya tiene vello púbico en sus órganos sexuales utilizando la palabra estuche como metáfora eufemística.

d. Ta' chin, calabacín (FN10) donde la apócope de chingón mediante la forma chin funciona como un eufemismo en este juego, que se utiliza para señalar que algo está chingón, es decir, 'muy padre' o 'muy bien'.

e. Tan dura como verdura (FN10), donde verdura sustituye a verga en esta expresión que funciona como un símil para señalar que algo es duro como la erección del órgano sexual masculino. Cabe señalar que en este caso también uno puede quedarse solamente con el significado composicional de la expresión, por lo que tendría dos lecturas posibles, pues también existen verduras que presentan una consistencia dura. 


\subsection{El uso de nombres propios como formas parónimas y alargamientos}

La presencia de nombres propios es bastante común en los juegos verbales presentados, sin embargo, encuentro casos en los que tanto la forma parónima que funciona como el núcleo del juego como los elementos léxicos que se incrustan para alargarlo son apellidos o topónimos:

a. Vásquez Velásquez (JB13), donde el apellido Vásquez sustituye a la palabra vas para manifestar que se está de acuerdo con lo que el interlocutor está planteando y Velásquez funciona como elemento léxico que complementa y alarga el juego.

b. ¿Qué Pachuca por Toluca? (DDEM19), que se utiliza como variante del saludo ‘iQué pasó?’ y donde el topónimo Pachuca sustituye a la palabra pasó y el topónimo Toluca sirve para alargar el juego.

\subsection{Metáforas}

Otra de las técnicas discursivas que se repite en este subconjunto de datos en los que el juego apela tanto al plano de la expresión como al plano del contenido es el uso de metáforas:

a. Este osito de peluche ya se va para su estuche (FN10), donde estuche se utiliza como metáfora de 'casa' en este dicho que se utiliza para despedirse.

b. Relaja la raja y disfruta la fruta (FN10), donde el vocablo raja significa de manera metafórica ya sea 'vulva de la mujer' o 'ano' y fruta significa 'órgano sexual masculino.

c. Esta rorra se les borra (DDEM19), donde el significado de borrar se utiliza en el sentido metafórica de 'irse', en esta expresión que utilizaría una mujer para despedirse de alguna fiesta o entre gente muy cercana.

\subsection{Elementos que forman parte de un mismo campo léxico}

Otra técnica discursiva que es de llamar la atención es el uso de dos o más vocablos que forman parte de un mismo campo léxico. En estos casos se observa que el 
significado de la forma yuxtapuesta se convierte en el núcleo o la base para generar un juego pluriléxico que en sí mismo puede tener un significado composicional:

a. Cámara, que funciona como una interjección para señalar que se está de acuerdo con lo propuesto por otra persona, genera la expresión en Cámara, pivote y rin, Mickey, Pluto y Tribilin (DDEM19), donde el primer verso se estructura mediante vocablos que denominan partes de la llanta de automóvil como la cámara, el pivote y el rin, mientras que el segundo verso asocia el nombre propio de algunos de los personajes más conocidos de Disney como Mickey, Pluto y Tribilín.

b. Nos vemos al rato se transforma en Nos vemos al ratón le gusta el queso y a la ardilla, la tortilla (RC15), donde se asocian dos animales roedores como el ratón y la ardilla y dos alimentos como el queso y la tortilla.

c. A partir de la interjección va, que se usa para confirmar o mostrar que se está de acuerdo con alguna propuesta o invitación, surge la expresión Bambi es un venado y Tambor su valedor (DDEM19), donde nuevamente hay una asociación entre dos personajes Disney que forman parte de la película de dibujos animados Bambi.

d. El saludo ¿Qué pasó? pasa aQué epazotes con los ejotes? (FN10), donde se observa la asociación entre el epazote que se usa como condimento para distintos platillos mexicanos y una vaina comestible como el ejote.

e. De la interjección cámara surge la expresión popular camarón, pulpo y ostión (Chilangonario), donde se observa la asociación entre el camarón, el pulpo y el ostión, como tipos de mariscos que se consumen mucho en México.

\section{CONSIDERACIONES FINALES}

A lo largo de este trabajo he presentado un primer acercamiento a algunos juegos verbales documentados en el español de México. Después de caracterizar la noción de juego verbal y de mencionar buena parte del repertorio de técnicas discursivas que los hablantes emplean en su construcción, determiné circunscribir este estudio a aquellos datos que se estructuran mediante el uso de rimas consonantes. Mediante esta decisión metodológica, pude aproximarme a estos datos desde tres ejes de análisis: su comportamiento como actos de habla, la descripción de su estructura rítmica y la elaboración de algunas observaciones generales en cuanto a su posible motivación lingüística. 
En el caso del acercamiento a estos juegos verbales como actos de habla, queda claro que para comprender a plenitud la naturaleza de estas manifestaciones lingüísticas se debe contemplar que se trata de un fenómeno cuya gestación se da en la actividad dialógica que se establece entre las personas de manera cotidiana (Lara, 2012); por ende, se vuelve necesario pensar en la elaboración de trabajos que profundicen en la dimensión pragmática de estas maneras de decir que constituyen el núcleo de las tradiciones verbales populares; pues cada juego verbal surge y cobra sentido en determinadas situaciones de la vida social.

En relación al cómputo silábico y al patrón rítmico de los datos analizados, se confirma la preeminencia del metro octosílabo como la estructura métrica por excelencia en la tradición popular, como lo demuestra su presencia desde las paremias medievales (Bizarri, 2014; Pla, 2017); de igual modo, la recurrencia de la rima consonante como técnica discursiva posibilita que estos juegos se vuelvan memorables gracias a esta figura retórica que permite su repetición, transmisión y conservación en el imaginario social. De manera que, al igual que el pensamiento metafórico forma parte esencial de nuestra experiencia lingüística (Lakoff y Johnson, 1980), la expresividad, el dinamismo y la belleza de las figuras literarias que afectan la forma de la expresión de los signos lingüísticos también participan en nuestros decires cotidianos cuya herencia impulsa buena parte de nuestra competencia comunicativa.

Por último, el análisis de la motivación de estos juegos verbales me ha permitido detectar algunas otras técnicas discursivas, como la metáfora, el eufemismo o la doble lectura, que contribuyen a valorar la complejidad y el ingenio que aflora en estas prácticas lingüísticas cuya vivacidad, espontaneidad y agudeza son dignas de reflexión y descripción desde la ciencia del lenguaje.

\section{FUENTES PRIMARIAS}

BOyer, Julie (2013): Forma y función de los juegos fónicos en el habla juvenil de Puebla, Tesis de maestría, Canada, Faculté des arts et sciences, Université de Montréal. Cabulario = Rojas, Alberto y Eduardo Ruiz (2015): El Cabulario de Beto y Lalo Co, México, Algarabía.

Colaborador ( 14 de julio de 2015): «Frases que dicen que decimos los chilangos al saludar». En línea <https://www.chilango.com/general/frases-que-decimos-los-chilangos-al-saludar $>$ [07/03/2019].

Chilangonario = Peralta de Legarreta, Alberto (2012): El Chilangonario: Vocabulario de supervivencia para el visitante de la Ciudad de México, México, Algarabía. 
Chingonario $=$ Montes de OCA Sicilia, Pilar (2010): El Chingonario: diccionario de uso, reuso y abuso del chingar y sus derivados, México, Algarabía.

DEM = LARA, Luis. Fernando (dir.), (2019[2010]): Diccionario del español de México, 2a ed., El Colegio de México, A.C. En línea <http://dem.colmex.mx>.

Diccionario naco (19 de febrero de 2008): «Diccionario Naco». En línea: <https://marcianosmx.com/diccionario-naco/> [09/03/2019].

GuZMán, Lorena (en proceso de elaboración): Juegos verbales de afirmación y negación en el español de la Ciudad de México: un estudio lexicológico, Tesis de licenciatura, México, Escuela Nacional de Antropología e Historia.

LARA, Luis. Fernando (dir.) (2019): Documentación lexicográfica para el proyecto del Diccionario del español de México.

Lope Blanch, Juan Manuel (1980): «Algunos juegos de palabras en el español de México», Lingüistica Española Actual, II (1), pp. 219-243.

Nirvanero (23 de febrero de 2010): «Frases nacas». En línea: <http://expresionateloquequieras.blogspot.com/2010/02/frases-nacas.html > [07/03/2019].

REDACCIÓN (febrero de 2017). «Lugares comunes». En línea: <https://www.chilango.com/chilangonol/lugares-comunes $>$ [08/03/2019].

UVM = MANJARREZ, Héctor (2011): Útily muy ameno vocabulario para entender a los mexicanos. México. Grijalbo.

S/N (14 de noviembre de 2016): «50 dichos mexicanos de barrio». En línea: <https://masdemx.com/2016/11/refranes-dichos-mexicanos-de-barrio-barriales-calle/> [08/03/2019].

\section{BIBLIOGRAFÍA}

Anscombre, Jean-Claude (1999): «Estructura métrica y función semántica de los refranes», Paremia, 8, pp. 25-36.

Anscombre, Jean-Claude (2000): «Refranes, polilexicalidad y expresiones fijas», en María Luz Casal Silva, Germán Conde Tarrío, Jesús Lago Garabatos, Laura Pino Serrano y Nuria Rodríguez Pedreira (eds.), La lingüistica francesa en España camino del siglo XXI, España, Arrecife, pp. 33-53.

Anscombre, Jean-Claude (2012): «Matrices rythmiques et parémies», en Jean-Claude Anscombre, Bernard Darbord y Alexandra Oddo (cords.), La parole exemplaire. Introduction à une étude linguistique des proverbes, París, Armand Collin, pp. 147-158.

Austin, John L. (1962): How to Do Things with Words, Oxford, Clarendon Press. BAHER, Rudolf (1970): Manual de versificación española, Madrid, Gredos. 
Bizzari, Hugo O. (2004): El refranero castellano en la Edad Media, Madrid, Laberinto.

BüHLER, Karl (1934): Sprachtheorie: Die Darstellungsfunktion der Sprache, Jena, Fischer.

Corpas Pastor, Gloria (1996): Manual de fraseología española, Madrid, Gredos.

Coseriu, Eugenio (1992[1988]): Competencia lingüistica. Elementos de la teoría del hablar, Madrid, Gredos.

Coseriu, Eugenio (1981): Lecciones de lingüistica general, Madrid, Gredos.

Coseriu, Eugenio (1977): «Introducción al estudio estructural de léxico», en Principios de semántica estructural, Madrid, Gredos, pp. 87-142.

Coseriu, Eugenio (2001): «Quelques thèses à propos de l'essence du langage et du signifié», en Dominique Keller, Jean Pierre Durafour, Jean François Bonnot y Rudolph Sock, (eds.), Percevoir: monde et langage. Invariance et variabilité du sens vécu, Sprimont, Mardaga, pp. 79-92.

Domínguez Caparrós, José (1985): Diccionario de métrica española, Madrid, Paraninfo.

Domínguez Caparrós, José (2014): Métrica española, Madrid, UNED.

Domínguez CAparrós, José (2016): «El canon variable del verso español», Actio Nova. Revista de Teoría de la Literatura y Literatura Comparada, 0, pp. 79-92.

ENgler, Rudolf (1964): «Complements à l'arbitraire», Cabiers Ferdinand de Saussure, 21, pp. 25-32.

FRENK, Margit (1961): «Refranes cantados y cantares proverbializados», Nueva Revista de Filología Hispánica, 15, pp. 155-168.

Guiraud, Pierre (1975 [1955]): La sémantique, París, Presses Universitaires de France.

Hjelmslev, Louis (1971[1943]): Prolegómenos a una teoría del lenguaje, Madrid, Gredos.

KabATEK, Johannes (2015): «Wordplay and Discourse Traditions», en Angelika Zirker Angelika y Esme Winter-Froemel (eds.), Wordplay and Metalinguistic / Metadiscursive Reflection: Authors, Contexts, Techniques, and Meta-Reflection (The Dynamics of Wordplay 1), Berlín \& Boston, De Gruyter, pp. 213-228.

Lakoff, George, y Johnson, Mark (1980): Metaphors we live by, Chicago, Chicago University Press.

Lara, Luis F. (2006): Curso de lexicología, México, El Colegio de México.

LARA Luis F. (2009): «No “normas”, sino tradiciones», en Lengua histórica y normatividad, 2. ${ }^{\text {e }}$ d. corregida y aumentada, México, El Colegio de México, pp. 71-93. 
LARA, Luis F. (2012): «Hacia una tipología de las tradiciones verbales populares», Nueva Revista de Filología Hispánica, 60 (1), pp. 51-60.

LARA, Luis F. (2014): «La noción de tradición verbal y su valor para la lingüística histórica », Nueva Revista de Filología Hispánica, 62 (2), pp. 505-514.

Lewandowski, Theodor (1982): Diccionario de lingüistica, Madrid, Cátedra.

Lope Blanch, Juan M. (1980): «Algunos juegos de palabras en el español de México», Lingüistica Española Actual, II (1), pp. 219-243.

Morawski, Joseph (1927): «Les formules rimées de la langue espagnole», Revista de Filologia Española, XIV, pp. 113-133.

Navarro Tomás, Tomás (1973): Los poetas en sus versos: desde Jorge Manrique a García Lorca, Barcelona, Ediciones Ariel.

Navarro Tomás, Tomás (1975[1959]): Arte del verso, México, Colección Málaga.

ODDo, Alexandra (2015): «Historia de una pareja inseparable: el ritmo en el refranero español», Rhytmica, XIII, pp. 173-192.

Oesterreicher, Wulf (1997): «Zur Fundierung von Diskurstraditionen», en Barbara Frank, Thomas Haye y Doris Tophinke (eds.), Gattungen mittelalterlicher Schriftlichkeit, Tubinga, Gunter, Narr Verlag Tübingen, pp. 19-41

PARDo, Arcadio (2004): «Verso aislado, verso solo, verso-poema », Rhytmica, II, pp. 201-233.

Pardo, Madeleine y Arcadio PARdo (2010): Précis de métrique espagnole, París, Armand Colin.

Pla Colomer, Francisco P. (2017): «Fundamentos para una fraseometría histórica del español», Rhytmica, XV, pp. 87-112.

PRESEEA (2014): «Guía de Estudios de la Atenuación en los corpus PRESEEA». En línea: <www.preseea.linguas.net.> [14/05/2019].

Quesada, J. Diego (1999): «Algunos juegos de palabras en el español: muestra y análisis estructural », Lexis, 1, pp. 167-180.

Quilis, Antonio (2007[1984]): Métrica española, Barcelona, Ariel.

SAussure, Ferdinand de (1972[1916]): Cours de linguistique générale, París, Payot.

Searle, John R. (1969): Speech Acts. An Essay in the Philosophy of Language, Cambridge, Cambridge University Press.

Searle, John R. (1991): «What is a Speech Act?», en Steven Davis (ed.), Pragmatics: A Reader, Nueva York/Oxford, Oxford University Press, pp. 254-264.

SánChez de la BARQuera Cortez, Ana M.a (2014): Variación semántico-léxica en español mexicano: Estudio sociolingüistico de dos redes sociales, Tesis de licenciatura, Puebla, Benemérita Universidad Autónoma de Puebla. 
Solano Rodríguez, María Ángeles (2012): «Las unidades fraseológicas del francés y del español: tipología y clasificación », Paremia, 21, pp. 117-128.

TAYlor, John R. (2006): «Motivation», en JCLA (Proceedings of the Sixth Annual Meeting of the Japanese Cognitive Linguistics Association), 6, pp. 486-502.

Thaler, Verena (2016): «Varieties of Wordplay», en Sebastian Knospe, Alexander Onysko, Maik Goth, (eds), Crossing Languages to Play with Words. Multidisciplinary Perspectives (The Dynamics of Wordplay, 3), Berlín/Boston, De Gruyter, pp. 47-62.

Zuluaga, Alberto (1980): Introducción al estudio de las expresiones fijas, Frankfurt, Peter Lang.

Fecha de recepción: 19 de julio de 2019 Fecha de aceptación: 24 de octubre de 2019 